\title{
Developing Hydrodynamic and Sediment Transport Modelling on Lakes: A Preliminary Study
}

\author{
Rian Mantasa Salve Prastica, Herr Soeryantono, and Dwinanti Rika Marthanty
}

\begin{abstract}
Lakes in Universitas Indonesia (UI) have several problems to overcome. Water quality of UI's lakes degrades in the last decade. One of the problems is high turbidity. The longer turbidity in lakes, the more dangerous the lakes environment life would be. So, this research focuses on sediments problem or physical assessment. The main research aims to develop hydrodynamic and sediment transport modelling of Agathis and Mahoni Lakes in Universitas Indonesia. The authors want to increase the quality of water in UI's lakes and make both Agathis and Mahoni Lakes as the representative preliminary model. Research design or methodology is needed to concept the research to achieve goals. Unfortunately, research methodology has not been developed yet for this case. This paper goals to construct methodology as a preliminary study of the main research. The authors use extensive literature review to model novel methodology. Hydrodynamic and sediment transport modelling could be modelled by Resources Modelling Associates (RMA). Hydrodynamic phenomena in fluid and sediment transport modelling have the suitable governing equation concept with RMA's governing equation. As a thinking result, the main research would be conducted by RMA program modelling, field sampling, and laboratory testing. Field sampling and laboratory could figure the amount of sediment concentration in lakes as data input. The final simulation of this following research is making sensitivity and scenario analysis to prove several hypotheses.
\end{abstract}

Index Terms-Hydrodynamic modelling, RMA program, sediment transport.

\section{INTRODUCTION}

Lakes are life, so their existences are important to notice. Lakes include raw water resources category [1]. The quality of raw water is a critical indicator for environment [2], [3]. However, people today have less water for themselves, livestock, and plants. Raw water is two percent of earth's groundwater [4]. In addition, it is the most decreasing and changing ecosystem [5]. Lakes ecosystem consists of physical, chemical, and biological characteristics in the water body. The interaction among them could be studied, understood, and used for effective lakes management [1].

Recent days, the effort to do lakes conservation is difficult

Manuscript received November 20, 2017; revised December 20, 2017. This work was supported by Indonesia Endowment Fund for Education or Lembaga Pengelola Dana Pendidikan (LPDP) under LPDP Research Grant. This organization is under The Ministry of Finance of Indonesia.

Rian Mantasa Salve Prastica is with Civil Engineering Department of Engineering Faculty, Universitas Indonesia, Depok, West Java, 16424 Indonesia (e-mail: rianmantasasp@gmail.com, rian.mantasa@ui.ac.id).

Herr Soeryantono and Dwinanti Rika Marthanty are with Water Resources Management Group, Civil Engineering Department, Faculty of Engineering, Universitas Indonesia, Depok, West Java, 16424, Indonesia (e-mail: herrsoeryantono@ui.ac.id). to do for several reasons. The threat of biodiversity decreasing in raw water ecosystem could be affected from various factors: uncontrollable exploitation, water pollution, stream modification, damage habitat, and exotic species invasion [6]-[9]. Environment changes globally. Nitrogen deposition, temperature increasing, and rainfall pattern changes are supportive factors for environment threat [10], [11].

In the past years, people controlled water through on-stream approach. They regulated rivers. Today, off-stream approach usage is highly increasing. This approach involves retention pond and infiltration wells.

Jakarta has been implemented the on-stream approach to regulate its water. The Jakarta's government constructs lakes system. So does Depok's government. There are hundreds of lakes in both Jakarta and Depok regions. These lakes could have optimum hydrological function if they are preserved But, the society paradigm becomes a barrier. The lakes become garbage and waste water dumping site. Furthermore, they give negative effects, for examples, creating living habitat for mosquitos, becoming water-borne diseases trigger, and producing bad odor. To increase the land value, the society prefer to hoard the lakes with soil. The example is Pedongkelan Lake that is located in Jakarta-Depok boundary. Its water body area is decreasing because of land filling in the lake.

Universitas Indonesia (UI), which is located in Depok, West Java, has started to increase the effort of making better water quality. UI has six lakes, namely Kenanga, Agathis, Mahoni, Puspa, Ulin, and Salam lakes. UI as educational institution should become role model to manage healthy lake to the students and society. However, UI's lakes quality is deteriorating in the last five years.

UI plans several systems: debris removal, sediments removal, and nutrients removal. These efforts are highly suggested to be conducted, so the lakes could perform well in hydrological function. These could affect to restore water quality and biotic life.

This proposed problem needs a model simulation to do water resources management effectively and efficiently. Several simulators have been examined, for example, phosphorous and nitrogen distribution simulator. However, sediment distribution simulator is not developed and technologically advanced yet. The simulator could be modelled for hydrodynamic and sediment transport.

Hydrodynamic and sediment transport models could be used as water quality model for lakes ecosystem response to various change or condition.

According to these general problems, a solution is needed to make lakes or ponds become physically, chemically, and biologically sanitary. This research aims to find a 
methodology to conduct hydrodynamic and sediment transport modelling on lakes.

\section{LITERATURE REVIEW}

\section{A. Pollutant Sources}

According to research in Kariba Lake [12], the main pollutant source in lakes comes from urban and industrial activities, mining, agro-chemistry substances, and aquaculture. The other research in Colac Lake mentions that the pollutant comes from water inflow, outflow, and sediment input [13]. Inflow and outflow come from various sources. Water bodies receive water flow from wastewater from local waste treatment. Water in the lake is reported to be overflowing due to the long rainfall intensity with high rainfall. This result in the inclusion of various solid or liquid wastes carried into the water body when water returns to normal conditions. Incoming sediments then settle into Lake Colac through natural processes such as carried by the flood that occurred. Based on this phenomenon, this research aims to focus on sediment pollutant.

\section{B. Sediment Treatment Strategy}

Water discharges in roadways, roofs, and parking lots get high attention because of its impact, such as high flooding frequency, bad water quality in the water body, and downstream ecosystem risk [14]-[16]. The treatment to control water quality is important to increase water quality for environment and life.

One example of strategies is a retention pond. It is the most used strategy for Best Management Practices (BMP) to control water discharges. The other most used plans are sediment trap and wetland.

\section{Wetlands}

The using of constructed wetlands $(\mathrm{CW})$ as pollutant control is reaching four decades today. It controls pollutant loading from wastewater system, industrial wastewater, agricultural wastewater, and stormwater [17].

\section{Lakes and Impoundments}

Chapra [18] states that the initial stage to do lake or impoundment simulation is determining the geometry or morphometry. This stage could be done by mapping lake's bathymetry. Bathymetry represents a topographic map of depth contour lines.

The equation that represents a water balance for a well-mixed lake is

$$
S=\frac{d V}{d t}=Q_{\text {in }}-Q_{\text {out }}+G+P A_{s}-E A_{s}
$$

where $S=$ storage $\left(\mathrm{m}^{3} \mathrm{~d}^{-1}\right), \mathrm{V}=$ volume $\left(\mathrm{m}^{3}\right), \mathrm{t}=$ time $(\mathrm{d}), \mathrm{Q}_{\text {in }}$ = inflow $\left(\mathrm{m}^{3} \mathrm{~d}^{-1}\right), \mathrm{Q}_{\text {out }}=$ outflow $\left(\mathrm{m}^{3} \mathrm{~d}^{-1}\right), \mathrm{G}=$ groundwater flow $\left(\mathrm{m}^{3} \mathrm{~d}^{-1}\right), \mathrm{P}=$ precipitation $\left(\mathrm{md}^{-1}\right), \mathrm{E}=$ evaporation $\left(\mathrm{md}^{-1}\right)$, and As $=$ surface area $\left(\mathrm{m}^{2}\right)$. The equation could be used for two general fashions: steady state and time vaiable.

\section{WATER QUALITY MODELLING}

Water quality modelling research gets high interest for researchers in the last decade. Water quality becomes both national and international issue which immediately needs to be overcome. At the same time, several organizations and institutions create both hardware and software to support the research.

\section{A. Water Quality Modelling in Lakes}

Chapra [18] observes that three categories could make different kinds of lakes. The classifications are according to derivation, formation, and size. Different types of loading are classified also. There are impulse loading, step loading, linear loading, exponential loading, and sinusoidal loading.

\section{B. Sediment Transport}

When sediments enter the water body, they are moved and transformed with various mechanisms. The part of solid would disappear because of decomposition. The residual organic particle with nonorganic solid become movement object.

\section{Total Suspended Solid (TSS) Model}

Braskerud [19] shows that steady state condition in CW, where the flow velocity is relatively low, settling is the dominant process to decrease the amount of TSS. Chavan and Dennet [20] give the equation of settling velocity as the following form.

$$
V_{\text {settling }}=\operatorname{gxd}_{s s}^{2} x\left(\frac{S_{g}-1}{18 x v}\right)
$$

The sediment settling velocity is represented as $V_{\text {settling }}, g$ represents gravitational acceleration, $d_{s s}$ represents sediment particle diameter, $S_{g}$ as particle specific gravity, and $v$ represents water kinematic viscosity.

\section{Stokes Law}

According to Potter [21], continuity equation could be written by applying mass conservation in control volume, where flux inflow in the element surface is equal to mass changes in the element. The following equations are the derivation of mass conservation principles for this research model.

$$
m_{\text {in }}-m_{\text {out }}=\frac{\partial}{\partial t} m_{\text {element }}
$$

The equation above results in the following equation.

$$
\frac{\partial \rho}{\partial t}+u \frac{\partial \rho}{\partial x}+v \frac{\partial \rho}{\partial y}+w \frac{\partial \rho}{\partial z}+\rho\left(\frac{\partial u}{\partial x}+\frac{\partial v}{\partial y}+\frac{\partial w}{\partial z}\right)=0
$$

Then, the previous equation simplifies these equations, where they are involved in general form from continuity equation at Cartesian coordinate.

$$
\frac{D \rho}{d t}+\rho\left(\frac{\partial u}{\partial x}+\frac{\partial v}{\partial y}+\frac{\partial w}{\partial z}\right)=0
$$

If operator gradient, del, is presented, it results: 


$$
\nabla=\frac{\partial}{\partial x} \hat{i}+\frac{\partial}{\partial y} \hat{j}+\frac{\partial}{\partial z} \hat{k}
$$

Furthermore, the continuity equation could form:

$$
\frac{D \rho}{d t}+\rho \nabla \cdot V=0
$$

According to Newton $2^{\text {nd }}$ Law, $F=$ ma, so fluid particle at $\mathrm{x}, \mathrm{y}$, and $\mathrm{z}$-direction become:

$$
\begin{gathered}
\frac{\partial \sigma_{x x}}{\partial x}+\frac{\partial \tau_{y x}}{\partial y}+\frac{\partial \tau_{z x}}{\partial z}+\rho g_{x}=\rho \frac{D u}{D t} \\
\frac{\partial \sigma_{y y}}{\partial y}+\frac{\partial \tau_{x y}}{\partial x}+\frac{\partial \tau_{z y}}{\partial z}+\rho g_{y}=\rho \frac{D v}{D t} \\
\frac{\partial \sigma_{z z}}{\partial z}+\frac{\partial \tau_{x z}}{\partial x}+\frac{\partial \tau_{y z}}{\partial y}+\rho g_{y}=\rho \frac{D w}{D t}
\end{gathered}
$$

\section{MATHEMATICS MODEL}

Mathematics model represents project area in one, two, or three-dimensional form. The one-dimensional model contains cross section is single linear scale. It is modelled according to the hydraulic condition in the computed cross sections. Two-dimensional model represents length and width of lakes. It is assumed that water is well mixed and its velocity is averaged vertically. Two-dimensional model figures hydraulic condition in a spatial grid in lakes. Furthermore, the three-dimensional model represents length, width, and depth. It is used to give complex hydraulic characteristics like the stratified flow and vertical turbulence.

In this research, two-dimensional model and three-dimensional model could be used according to its purposes. Two-dimensional model predicts flow velocity and depth in lakes. This model assumes the velocity is averaged vertically and not involved stratification as consideration in the model.

Several hydrodynamic models compute three-dimensional flow - length, width, and depth. It is used when width and depth of water are assumed as variables, especially for water body with varied of salinity, temperature, and sediment loading.

A numerical solution is used to analysis hydrodynamic which has iterative computation procedure to solve mathematical expression with no unique solution.

There are three principles of numerical modelling: finite differences, finite elements, and finite volumes. Finite difference model uses time interval and limited space with a regular grid. Finite element processes steps through the simultaneous equation for a discrete element like element rows in the two-dimensional grid. The finite volume combines finite element capability to represent complex bathymetry with mass and volume conservation which is done by finite difference.

RMA2 is well known to be used in numerical modelling for the two-dimensional model. The cooperation between the
US Geological Survey and Federal Highway Administration develops two-dimensional hydrodynamic public domain model. It is called Finite Element Surface Water Modeling System. This model studies about hydrodynamic in two-dimensional phase in river, lakes, reservoirs, or estuaries. It could predict physical process (sediment transport), chemical process (dissolved oxygen, nutrients), or biological process (bacteria transport) by using advection, dispersion, diffusion, and decay. Finally, the finite element is chosen to be numerical model governing equation for this research.

There are four recommended program Simulator program that used in this proposed research [22]. They are RMA-10, RMA-11, UNTRIM, and EFDC. These programs have 3-D dynamic and unsteady concept. Besides that, they simulate water quality modelling. However, the chosen program is RMA program because of its availability in Civil Engineering Department of Universitas Indonesia. RMA-10 has hydraulic governing equation and RMA-11 has advection-dispersion governing equations.

\section{HYDRODYNAMIC PROCESS}

Hydrodynamic process is complex surface water system. Water flows at varied scales and types are highly affected not only the circulation of temperature, nutrients, and dissolved oxygen, but also the aggregation or circulation of sediments, contaminants, and algae.

\section{A. Water Density}

According to Ji [22], water density is a fundamental boundary in hydrodynamic and water quality studies. Hydrodynamic computation would be more comprehensive if the water density data is accurate. The density $(\rho)$ is determined by three variables: temperature $(\mathrm{T})$, salinity $(\mathrm{S})$, and concentration of total suspended sediment $(\mathrm{C})$. These parameters' relation could be observed as:

$$
\rho=f(T, S, C)
$$

The definite form of function $f$ could be examined empirically. The differential form of the equation above could be written as:

$$
d \rho=\left(\frac{\partial \rho}{\partial T}\right)_{S, C} d T+\left(\frac{\partial \rho}{\partial S}\right)_{T, C} d S+\left(\frac{\partial \rho}{\partial C}\right)_{T, S} d C
$$

Furthermore, it results:

$$
\rho=\rho_{T}+\Delta \rho_{S}+\Delta \rho_{C}
$$

\section{B. Conservation Laws}

Governing equation of the conservations laws involve the conservation of mass, the conservation of energy, and the conservation of momentum. These conservation laws are the basis of hydrodynamics. They are used for hydrodynamic and water quality modelling.

The law of conservation of mass states that mass can neither be produced nor destroyed. This law could be 
expressed in a mass balance equation. It is called the continuity equation. It is mass accumulation $=$ mass in - mass out + source - sink.

The equation above could be restated as

$$
d m=\left(m_{\text {in }}-m_{\text {out }}+m_{r}\right) \cdot d t
$$

An equation of mass flux could be stated by dividing with the time increment, $d t$. It would become the following mass balance equation:

$$
\frac{d m}{d t}=\frac{\partial m}{\partial t}+\nabla \cdot(m v)=m_{\text {in }}-m_{\text {out }}+m_{r}
$$

The conservation of momentum could be derived from Newton's second law:

$$
\stackrel{\mu}{F}=m \cdot \rho
$$

\section{Mass Balance}

The basic principle of mass balance equation could be observed from this discussion. Completely mixed system or well known as continuously stirred tank reactor (CSTR) is model who proposed by Chapra [18] to model natural water body. This characteristic is used as water quality modelling basic.

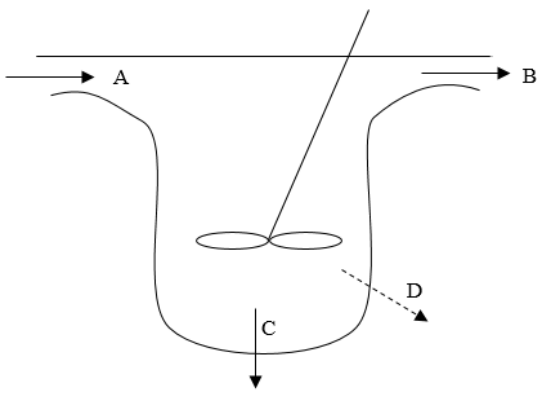

Fig. 1. CSTR scheme according to chapra [18].

Fig. 1 depicts the scheme of CSTR. There are four symbols presented in the figure. Symbol of A, B, C, and D represent loading, outflow, settling, and reaction respectively. The simple equation below is the form of the scheme which shows mass balance in the infinite period of time.

$$
\text { Accumulation }=\text { loading }- \text { outflow }- \text { reaction }- \text { settling }
$$

In this mass balance process, sink and source concept is highly fundamental. This concept figures a process in a system which affects the decreasing or increasing of substance's concentration in the system. Sink and source system consists of two mechanisms: physically and chemically. The physical mechanism could be settling process and chemical mechanism represents reactivity process. Ji [22] states that the mass balance equation is represented by the following equation.

$$
\frac{\partial C}{\partial t}=-U \frac{\partial C}{\partial x}+\frac{\partial}{\partial x}\left(D \frac{\partial C}{\partial x}\right)+S+R+Q
$$

According to the above equation, the first term, the second term, the third term, the fourth term, and the fifth term of equation represent advection process, dispersion process, settling, chemical and biological reaction in substances, and external loading respectively.

In the sediment transport modelling, the equation of mass balance changes into the following equation [22]. Then, it is called the governing equation of sediment transport.

$$
\begin{aligned}
& \partial_{t}(H S)+\partial_{x}(H u S)+\partial_{y}(H v S)+\partial_{z}\left(w_{s} S\right) \\
& =\partial_{x}\left(H A_{H} \partial_{x} S\right)+\partial_{y}\left(H A_{H} \partial_{y} S\right)+\partial_{z}\left(\frac{A_{v}}{H} \partial_{z} S\right)+Q_{s}
\end{aligned}
$$

where $H=$ the water depth, $u$ and $v=$ the horizontal velocity components in the Cartesian horizontal coordinates $x$ and $y, w$ $=$ the vertical velocity in the vertical sigma coordinate $z, w_{s}=$ the sediment settling velocity, $S=$ the diffusion coefficients, and $Q_{s}=$ external sources and sinks. The sediments movement in lakes represents advection and dispersion processes.

\section{Advection and Dispersion}

Advection describes flow horizontal movement that moves materials but not significantly dissolved [22]. The flux's density depends on concentration (C) and flows velocity

$(\bar{v})$. This phenomenon could be formed as the following equation.

$$
\overline{J_{a}}=C x \bar{v}
$$

Dispersion distributes contaminant horizontally. It involves the mixture of contaminant, which caused by turbulence and molecullar diffusion [23]. Dispersion in a longitudinal system generally is stronger than lateral system. Fick Law states that the movement of mass because of diffusion is the balance to the gradient from mass concentration and it depends disperse coefficient (D). The following equation figures this problem.

$$
J=-D \frac{\partial C}{\partial x}
$$

Furthermore, diffusion moves material from high concentration to low concentration. To make easier to understand about diffusion, you may imagine that a dye drops in the water-filled bottle. By matter of time, the colour would spread out in the whole water.

According to those phenomena, this research aims to use the governing equation of advection and dispersion to model sediment transport and water quality numerically. The governing equations in hydrodynamic processes are the principles which applied in Resources Modelling Associates (RMA) program.

\section{RESOURCES MODELLING ASSOCIATES}

The analysis of advection and dispersion in lakes could be done by using program that contains the numerical solution for both advection and dispersion governing equations. 


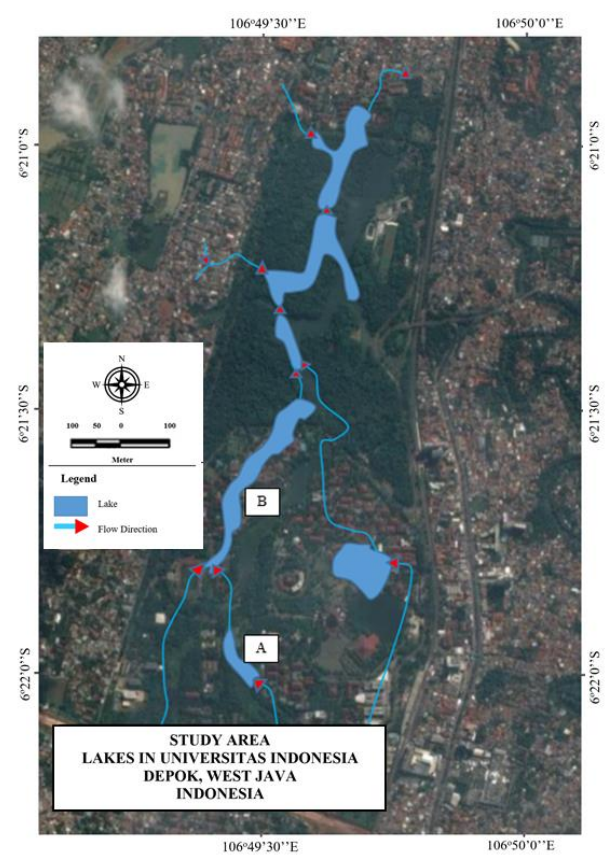

Fig. 2. Study area: Lakes in Universitas Indonesia.

Resources Modelling Associates (RMA) is engineering firm who applies software and numerical model to help to manage water resources and environmental changes. Four programs are provided to develop RMA: RMA-Gen, RMA-10, RMA-11, and RMA-PLT.

\section{A. RMA-GEN}

RMA-GEN or RMA Mesh Generator is a program that used to transform geometry to finite element model. This program needs several inputs: basic mal and bathymetry.

\section{B. RMA-10}

RMA-10 is three-dimensional model to simulate flow in estuary and velocity in flow depth. Navier-Stokes nonlinear equation is needed to describe the flow.

\section{RMA-11}

This program models water quality with finite element method to simulate estuary, lake, river, or coastal area in the three-dimensional model. RMA-11 models constituent in the water body: dissolved oxygen, temperature, nitrogen cycle, phosphorus cycle, and sediment. This program allows sediment transport governing equation.

\section{RMA-PLT}

RMA-PLT is used to display velocity vector, contour, and time variation from previous programs: RMA-10 and RMA-11.

RMA programs facilitate users to model hydrodynamic movement, both groundwater and water surface. Izzaty [23] states that these programs could rely on to model water quality. These programs provide data processing: map creation, flow simulation, constituent property, and their display.

\section{STUDY AREA}

Water quality problem in lakes is well known worldwide. It affects the environment to be worse. Macro invertebrate's life is in danger. Furthermore, it could affect human through varied diseases.

Universitas Indonesia (UI) is located in Depok, West Java, Indonesia. UI has six lakes. They are Kenanga, Agathis, Mahoni, Puspa, Ulin, and Salam Lakes.

This research aims to develop hydrodynamic and sediment transport modelling in UI. Lakes in UI have physical, chemical, and biological problems [23]-[25]. UI desires to make the lakes' water quality becomes better. Several types of research have been done by previous researchers. Fig. 2 depicts the entire system of lakes in Universitas Indonesia. However, this research goals to analyze only both Agathis and Mahoni Lakes. According to the figure, Agathis and Mahoni Lakes are symbolized with A and B respectively.

Area A and B in Fig. 2 next would be drawn according to their lakes' coordinates $x$ and $y$ from AutoCAD map into Ms. Excel-based. Fig. 3 depicts the distribution of coordinates from Agathis and Mahoni Lakes. Symbol A represents Agathis Lake and B characterizes Mahoni Lake. Next, the $x-y$ model should add bathymetry as $z$ coordinates to make $3 \mathrm{D}$ modelling in RMA program. This very beginning start is for RMA-GEN data input. The following program, RMA-10 and RMA-11 need more comprehensive data to run the programs. It would be discussed through literature review to develop the methodology.

\section{DISCUSSION}

In this section, the research plan is discussed. Rahmawati [26] has been conducted a research about river meander. This research connects with velocity vector which happened. Velocity vector in river meander is important to be reviewed with two or three-dimensional modelling, so numerical method is used to reach the goal. RMA is a software which could assist the research. It uses finite element method basic. Besides problems in the river, RMA could be used as the model simulator in lakes. Kusumah [24] developed RMA model as the simulator to predict phosphorous concentration distribution in Mahoni Lake. A year later, Izzaty [23] created pollutant transport modelling simulator by using two prototype lakes in UI: Agathis and Ulin Lakes. In the same year, Hermawan [25] conducted a research to simulate nitrogen concentration distribution in both Agathis and Ulin Lakes by using hydrodynamic modelling.

These previous types of research have several weaknesses. Initially, hydrodynamic modelling in lakes is limited to primary data. The researchers only use secondary data for data processing. So, some errors are found. Next, they model chemistry process only. Actually, chemical process modelling has been conducted. Li [27], Davis and Kent [28], and Dzombak [29] develop Fe and Mn tracing in lakes. However, Fortin et al [30] state that the result is difficult to find the physical characteristics of sediment in lakes.

Furthermore, this research field is developed by several next types of research. Wu and Li [31], Zahng and Liu [32], Zeng et al [33], and Liu and Shen [34] succeed in developing numerical model and hydrodynamic engineering for sediment transport. Liu and Shen [34] develop a simulation of three-dimensional turbulent modelling. It models sediment flow and transport and considers three-dimensional 
phenomena. However, three-dimensional modelling is more complex and expensive than 2D horizontal and 2D vertical modelling. According to Dongmiao [35] 2D horizontal modelling is considered as incompetent media to visualize flow variation and sediment. It is shown by considering depth The better result is figured by $2 \mathrm{D}$ vertical and $3 \mathrm{D}$ modelling.

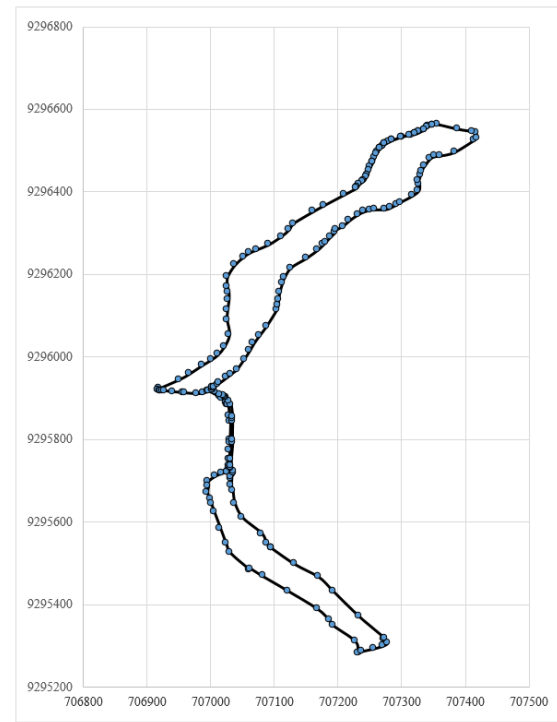

Fig. 3. Coordinates of Agathis and Mahoni lakes in $\mathrm{x}$ and $\mathrm{y}$ directions.

According to the previous types of research, this future research aims to simulate sediment transport and hydrodynamic modelling of lakes in UI. This research uses RMA program with finite element method as numerical modelling basic. This research output is hopefully could be considered as decision makers' decision to decrease sediment rate of lakes in UI.

This research has several limitations to focus. The study area is focused on Agathis and Mahoni Lakes. This research goals to develop sediment distribution simulator in both lakes. Field sampling and laboratory test would be conducted to obtain the better result. It is decided by previous types of research consideration. The determination of field sampling point would be decided from RMA-11 running program result which has been done by Kusumah [24], Izzaty [23] and Hermawan [25]. Constituents for RMA-11 are based on sediment transport model. They are total suspended solids (TSS), total dissolved solids (TDS), and turbidity. These parameters would be tested at Environmental Engineering Laboratory. Furthermore, according to the governing equation of sediment transport, velocity settling parameter is needed to be known. This parameter would be tested by sediment particle analysis which could be done at Mechanical Soil Laboratory.

Research design has several steps. Firstly, water quality phenomenon in the lakes is observed because of high turbidity. There are two assessments: hydraulic property and water quality. According to literature study, three hydraulic properties are needed: depth, velocity, and bathymetry. From depth parameter, water surface fluctuation could be observed Velocity distribution in the lakes could be visualized by velocity data. Furthermore, water quality is assessed physically. There are three constituents: TS, TDS, and turbidity. These parameters would visualize sediment distribution in the lakes. From these two assessments, sediment distribution simulation towards spatial and time could be studied.

The simulation would be performed by RMA program. Initially, RMA-GEN represents the coordinates and bathymetry of Agathis and Mahoni's lakes as the study area. The authors construct mesh in RMA-GEN with the finite element method based to analyze the detailed condition of lakes. Then, hydrodynamic modelling is simulated by RMA-10. It predicts velocity distribution. However, transport sediment modelling is worked by RMA-11. This program foresees sediment concentration distribution. Both RMA-10 and RMA-11 results should be validated by field sampling and laboratory tests.

Validation of RMA program output is needed to analyze the biases. Parameter validation for both RMA-10 and RMA-11 is according to the assessments parameter: hydraulic property and water quality.

The next step of this research is analyzing the biases between RMA program results and laboratory tests output. Furthermore, the results could be taken by decision makers to make lakes in Universitas Indonesia obtain better water quality.

The final step of the research is sensitivity analysis and scenarios simulation. Sensitivity analysis aims to give the description of sensitive parameters to the deviation. The result could recommend further analysis of data taking. Finally, scenarios simulation would be analyzed to predict several phenomena. Firstly, the scenario is increasing the loading concentration of sediments in the inflow. Second, decreasing the loading concentration amount in the inflow. Next scenario simulates loading type variation. Last, velocity variation would be simulated. These variations describe waste dumping pattern change to the water body. The expected result from the last hypothesis is the high concentration of sediment could be stop in the upstream part of the lakes cascade system. So, the downstream part of the lakes could have low concentration of sediments.

\section{CONCLUSION}

To conclude, this research aims to create sediment transport and hydrodynamic modelling of Agathis and Mahoni Lakes in Universitas Indonesia. This simulation would be done through Resources Modelling Associates (RMA) program. This program is highly recommended due to suitable governing equation phenomena for sediment transport, advection-dispersion, and hydraulic in lakes. This research would be conducted by creating the models through RMA program and validating the results with field sampling and laboratory tests. Furthermore, sensitivity analysis and scenarios' simulation would be analyzed for further comprehensive research. This methodology then would be applied to lakes in Universitas Indonesia with data collecting. When the research result could represent the real phenomena, this methodology then could be the basic methodology for all researchers with the same cases.

\section{ACKNOWLEDGMENT}


Rian Mantasa Salve Prastica expresses his appreciation as this study was conducted by the research funding of Indonesia Endowment for Education or Lembaga Pengelola Dana Pendidikan (LPDP) by the Ministry of Finance of Indonesia.

\section{REFERENCES}

[1] N. G. Hairston and G. F. Fussman, Lake Ecosystems. Encyclopedia of Life Sciences, London: Macmillan Publishers Ltd, 2002.

[2] US EPA, Water Quality Standards Handbook, Washington, D.C., USA United States Environmental Protection Agency, 1994.

[3] C. E. Williamson, J. E. Saros, W. F. Vincent, and J. P. Smol, "Lakes and reservoirs as sentinels, integrators, and regulators of climate change," Limnology and Oceanography, vol. 54, pp. 2273-2282, 2009.

[4] C. P. McDonald, E. G. Stets, R. G. Striegl, and D. Butman, "Inorganic carbon loading as a primary driver of dissolved carbon dioxide concentrations in the lakes and reservoirs of the contiguous United States," Global Biogeochemical Cycles vol. 2, pp. 285-295, 2013.

[5] S. R. Carpenter, E. H. Stanley, and M. J. Vander Zanden, "State of the world's freshwater ecosystems: physical, chemical, and biological changes," Annual Review of Environment and Resources, vol. 36, pp. 75-99, 2011

[6] B. Malmqvist and S. Rundle, "Threats to the running water ecosystems of the world," Environmental Conservation, vol. 29, pp. 134-153, 2002.

[7] F. J. Rahel, "Homogenization of freshwater faunas," Annual Review of Ecology and Systematics, vol. 33, pp. 291-315, 2002.

[8] S. Postel and B. Richter, Rivers for Life: Managing Water for People and Nature, Washington D. C., U. S. A: Island Press, 2003.

[9] C. Revenga, I. Campbell, R. Abell, P. Villiers, and M. Bryer, "Prospects for monitoring freshwater ecosystems towards the 2010 targets," Philos Trans R Soc B Biol Sci, vol. 360, pp. 397-413, 2005.

[10] N. L. Poff, M. M. Brinson, and J. W. J. Day, "Aquatic ecosystems and global climate change" Technical Report, Pew Center on Global Climate Change, Arlington, USA, 2002.

[11] J. N. Galloway, F. J. Dentener, D. G. Capone, E. W. Boyer et al., "Surface complexation modeling in aqueous geochemistry," Mineral-Water Interface Geochemistry, Reviews in Mineralogy, vol. 23, pp. 177-260, 1990.

[12] M. J. Tumbare, "Managing Lake Kariba sustainably: Threats and challenges," Management of Environmental Quality: An International Journal, vol. 19, issue 6, pp. 731-739, 2008.

[13] M. Khalifé, J. Gwyther, and J. Aberton, "Land use, water quality and ecological responses in Lake Colac - trends from Australia," Management of Environmental Quality: An International Journal, vol. 16 , issue 4, pp. 362-379, 2005.

[14] E. Eriksson, A. Bau, P. S. Mikkelsen, and A. Ledin, "Risk assessment of xenobiotics in stormwater discharged to Harrestrup $\AA$ Denmark," Desalin, vol. 215, pp. 187-197, 2007.

[15] A. D. McQueen, J. H. J. Johnson Rodgers, and W. R. English, "Campus parking lot stormwater runoff: physicochemical analyses and toxicity tests using Ceriodaphnia dubia and Pimephales promelas," Chemosphere, vol. 79, pp. 561-569, 2010.

[16] C. J. Walsh, T. D. Fletcher, and M. J. Burns, "Urban stormwater runoff: a new class of environmental flow problem," PLoS One, vol. 7, no. 9, p. e45814, 2012

[17] K. R. Reddy and E. M. D'Angelo, "Biogeochemical indicators to evaluate pollutant removal efficiency in constructed wetlands," Water Sci Technol., vol. vol. 35, no. 5, pp. 1-10, 1997.

[18] S. C. Chapra, Surface Water Quality Modelling, New York: McGraw-Hill International Editions, 1997.

[19] B. C. Braskerud, "Measurement and modelling of phosphorus retention in small constructed wetlands treating agricultural non-point source pollution," in Proc. 7th IWA Conference on Wetland Systems for Water Pollution Control. Institute of Food Agricultural Sciences, University of Florida, vol. 1, pp. 75-85, 2002.

[20] P. V. Chavan and K. E. Dennett, "Wetland simulation model for nitrogen, phosphorus, and sediments retention in constructed wetlands," Water, Air, and Soil Pollution, vol. 187, pp. 109-118, 2008

[21] M. C. Potter, D. C. Wiggert, B. Ramadan, and T. I. Shih, Mechanics of Fluids, Cengage Learning, 2012.

[22] Z. G. Ji, Hydrodynamics and Water Quality, New Jersey: John Wiley \& Sons, Inc, 2008.
[23] N. K. Izzaty, "Simulasi Distribusi pencemar fosfor di danau agathis dan Ulin universitas Indonesia dengan memanfaatkan program resources modelling associates (RMA)," B. Eng. Thesis, Dept. Civil Engineering, Universitas Indonesia, Depok, 2017.

[24] M. Kusumah, "Pengembangan Simulator untuk Distribusi Konsentrasi Fosfor 2D di Danau Mahoni Menggunakan Program Resources Modelling Associates (RMA)," B. Eng. Thesis, Dept. Civil Engineering, Universitas Indonesia, Depok, 2016

[25] A. Hermawan, "Simulasi Distribusi Konsentrasi nitrogen di danau agathis dan ulin kampus ui menggunakan program resources modelling associates (rma)," B. Eng. Thesis, Dept. Civil Engineering, Universitas Indonesia, Depok, 2017.

[26] E. Rahmawati, "Simulasi aliran dua dimensi dengan kedalaman rata-rata pada kelokan sungai mempergunakan program resources modelling associates (rma),” B. Eng. Thesis, Dept. Civil Engineering, Universitas Indonesia, Depok, 2011.

[27] Y. H. Li, "Ultimate removal mechanisms of elements from the ocean," Geochem. Cosmochem. Acta, vol. 45, pp. 1659-1664, 1981.

[28] J. N. Galloway, F. J. Dentener, D. G. Capone, E. W. Boyer et al., "Surface complexation modeling in aqueous geochemistry" Reviews in Mineralogy, vol. 23, pp. 177-260, 1990.

[29] D. A. Dzombak and F. M. M. Morel, In Surface Complexation Modeling: Hydrous Ferric Oxide, Wiley, 1990.

[30] D. Fortin, G. G. Leppard, and A. Tessier, "Characteristics of lacustrine diagenetic iron oxyhydroxides," Geochem. Cosmochem. Acta, vol. 57, pp. 4391-4404, 1993.

[31] T. Wu and X. X. Li, "Vertical 2-D mathematical model of sediment silting in dredged channel," Journal of Hydrodynamics, Series B, vol. 22, pp. 628-632, 2007.

[32] J. X. Zhang and H. Liu, "A vertical 2-D numerical simulation of suspended sediment transport," Journal of Hydrodynamics, Series B, vo. 19 , no. 2, pp. 217-224, 2007.

[33] J. Zeng, G. Constantinescu, and L. Weber, "A 3D nonhydrostatic model to predict flow and sediment transport in loose-bed channel bends," Journal of Hydraulic Research, vol. 46, no. 3, pp. 356-372, 2008.

[34] C. Liu and Y. M. Shen, "A three dimensional $k-\mathcal{E}-A_{p}$ model for water-sediment movement," International Journal of Sediment Research, vol. 25, no. 1, pp. 17-27, 2010.

[35] J. Tang et al., "Developing a 2D vertical flow and sediment transport model for open channels using the Youngs-VOF method," Chinese Journal of Oceanology and Limnology, vol. 35, no. 2 pp. 444-451, 2017.

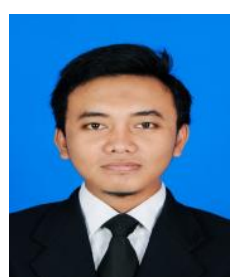

Rian Mantasa Salve Prastica is a master student in water resources management at Universitas Indonesia in Depok, Indonesia. He got his bachelor degree in 2015 from Universitas Sebelas Maret, Surakarta, Indonesia. His major is civil engineering. One of his research achievement is awarded as the best research about river transportation design in Java Island, Indonesia, in 2017, from Civil Engineering National Conference Committee in Universitas Tarumanagara, Jakarta, Indonesia.

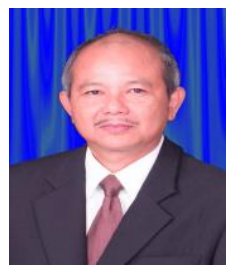

Herr Soeryantono is a senior lecturer in water resources management at Universitas Indonesia in Depok, Indonesia. He got his bachelor degree in 1981 from Universitas Indonesia. His major is civil engineering. He obtained his both master and Ph.D degree from Michigan State University, Michigan, USA. He studied in Civil and Environmental Engineering. He finished his master degree in 1987 and his Ph.D. degree in 1995.

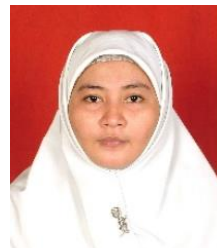

Dwinanti Rika Marthanty is a senior lecturer in water resources management at Universitas Indonesia in Depok, Indonesia. She got her bachelor degree in 2002 from Universitas Indonesia. Her major is civil engineering. She obtained her master degree from Universitas Indonesia in 2008. She concentrated on water resources management in her master degree. Her doctoral degree was obtained from Université de Lille 1, France, and Universitas Indonesia in 2016. She focused on hydrodynamics and computational fluid dynamics. 